\title{
RETRACTED ARTICLE: Endorectal MRI accuracy and its staging evaluation contribution in prostate cancer: a North African ethnic group
}

\author{
Abdellatif Janane - Fouad Hajji • Taher Ould Ismail • \\ Jean Crepin Elondo • Mohamed Ghadouan • \\ Ahmed Ameur • Mohamed Abbar
}

Received: 16 July 2010/Accepted: 24 August 2010/Published online: 29 September 2010

(C) Springer Science+Business Media, B.V. 2011

The article "Endorectal MRI accuracy and its staging evaluation contribution in prostate cancer: a North African ethnic group" has been retracted at the request of the editor because it contains significant verbiage plagiarizing another publication: "Endorectal MRI for prediction of tumor site, tumor size, and local extension of prostate cancer" (Nakashima et al (2004) Urology 64 (1):101-105).

A. Janane $(\bowtie) \cdot$ F. Hajji · T. O. Ismail ·

J. C. Elondo - M. Ghadouan - A. Ameur · M. Abbar

Urology Department, Great Military Universitary Hospital

Mohamed V, Rabat, Morocco

e-mail: a.janane@yahoo.fr 